\title{
PSYCHE.
}

\section{COLOR-VARIATION IN LARVAE OF PAPILIO POLYXENES, AND OTHER NOTES.}

BY CAROLINE G. SOULE, BROOKLINE, MASS.

In the summer of 1899 these butterflies were remarkably abundant in Brandon, Vt., and on many occasions I followed them from plant to plant collecting the eggs as fast as they were laid, keeping those of each butterfly by themselves.

Of more than 400 eggs the greater number were laid on caraway growing by the road, a few were on wild parsnip, and more than one third were on a patch of parsley in the garden, the whole patch not larger than a man's pocket handkerchief.

As the larvae grew they showed great variety in color and marks. In the stage following the third moult some were a little blacker than others.

After the fourth moult there was almost infinite variety, from those which were almost all grass-green with only hair-lines of black and very tiny yellow dots, to those which were almost wholly black with hair-lines of green, and yellow dots either very large or almost imperceptible.

But the greatest difference was shown by thirteen larvae which were absolutely without green at any stage of larval life, and were black and white, with yellow dots, in the last stage. The black varied much in these also, one or two specimens having only hairlines of white.

Food made no difference in the coloring, for all the larvae were fed chiefly on caraway, and all fared alike.

The black larvae came from eggs laid by butterflies whose other eggs gave normal larvae, and they passed through the four moults in every case. I had the larvae in tin boxes on my table, and examined them at least twice daily, and each tin contained so few larvae that I was able to be perfectly sure of the moulting of each one.

The chrysalids of these black larvae were of the brown type, with no black and no green about them, but several shades of brown. They were like twenty or thirty others formed by normal larvae.

Several of the normal larvae made bright green chrysalids with rows of yellow down the back.

Although the first chrysalids were formed on August 6th, and others were formed daily for many days, only three gave the butterfly, and all of these were of the green form, and these three never 
hardened, as did those which have not yet given the imago. This fact I noticed at the time, and kept watch of the chrysalids thinking that they might be going to decay.

Out of 55 chrysalids which I kept for myself only these three gave the butterfly, yet out of doors there were very many freshly emerged butterflies from August I6th until September 2oth, and these butterflies oviposited as plentifully as the earlier ones, giving larvae which pupated in October, the last one I know about pupating on October 2oth. I found small leaves of caraway bearing six, nine, thirteen, and fifteen eggs each, in different stages of development, as shown by their color. One butterfly only I saw lay two eggs on the same leaf, and these two were on different divisions of the leaf, one being on the under side, the other on the up- per side and close against another egg which had turned almost orange in color.

From watching the ovipositing I feel convinced that the butterfly does not see clearly, but depends very much on its antennae to distinguish between such plants as tansy and caraway. Several times a butterfly would fly to the low tansy leaves growing close by the caraway, and bend its abdomen to place the egg, when it would hesitate, touch the leaf with its antennae, and fly to another plant. If this proved caraway the egg would be laid.

The nearly full fed larvae preferred the green seeds of the caraway to the leaves.

Of all the larvae I reared from the egg or took from plants out of doors only one died, and that was stung by a tachinid.

\title{
PSEUDOPOMALA AND ITS ALLIES.
}

\author{
BY SAMUEL H. SCUDDER, CAMBRIDGE, MASS.
}

Pseudopomala was founded by Morse on an anomalous Acridian of New England (since found as far west as Utah) having a Tryxaline aspect, and which he placed in that subfamily and in this was followed by McNeill. On account of the distinct though slight pyramidal elevation on the prosternum I have since placed it in the Mesopes, a group otherwise confined to the Old World. It bears a close general resemblance to the oriental Gelastorhinus
Sauss., has a similar low prosternal spine, and an unmistakable Tryxaline aspect, due largely to the tricarinate pronotum and ensiform antennae, which it shares also with Opomala.

My opinion of its affinities has been strengthened by finding in our country another allied genus, whose type is Mesops cylindricus Brun., which has a similar prosternal prominence and in which the principal distinction from Pseudopomala lies in the absence of 

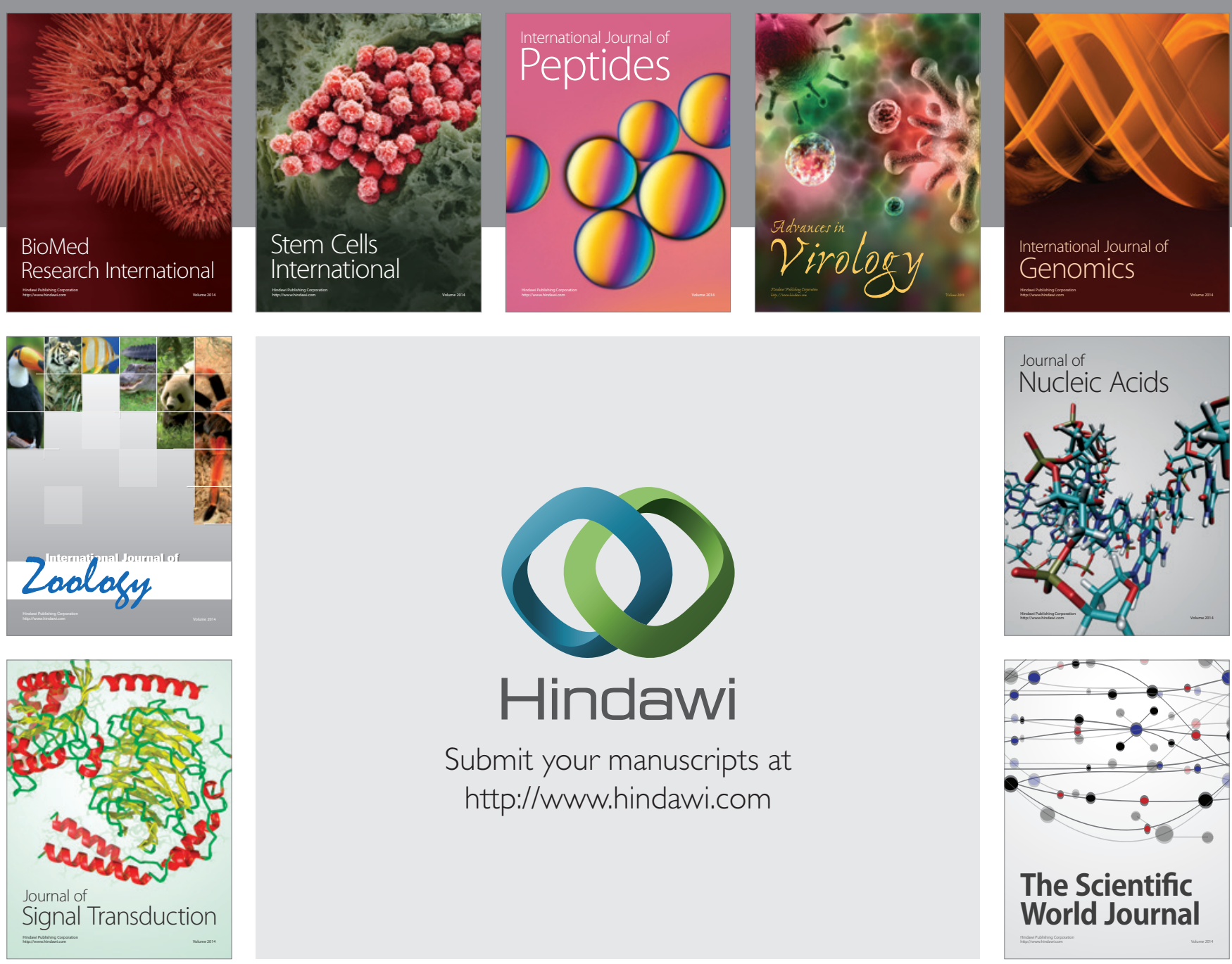

Submit your manuscripts at

http://www.hindawi.com
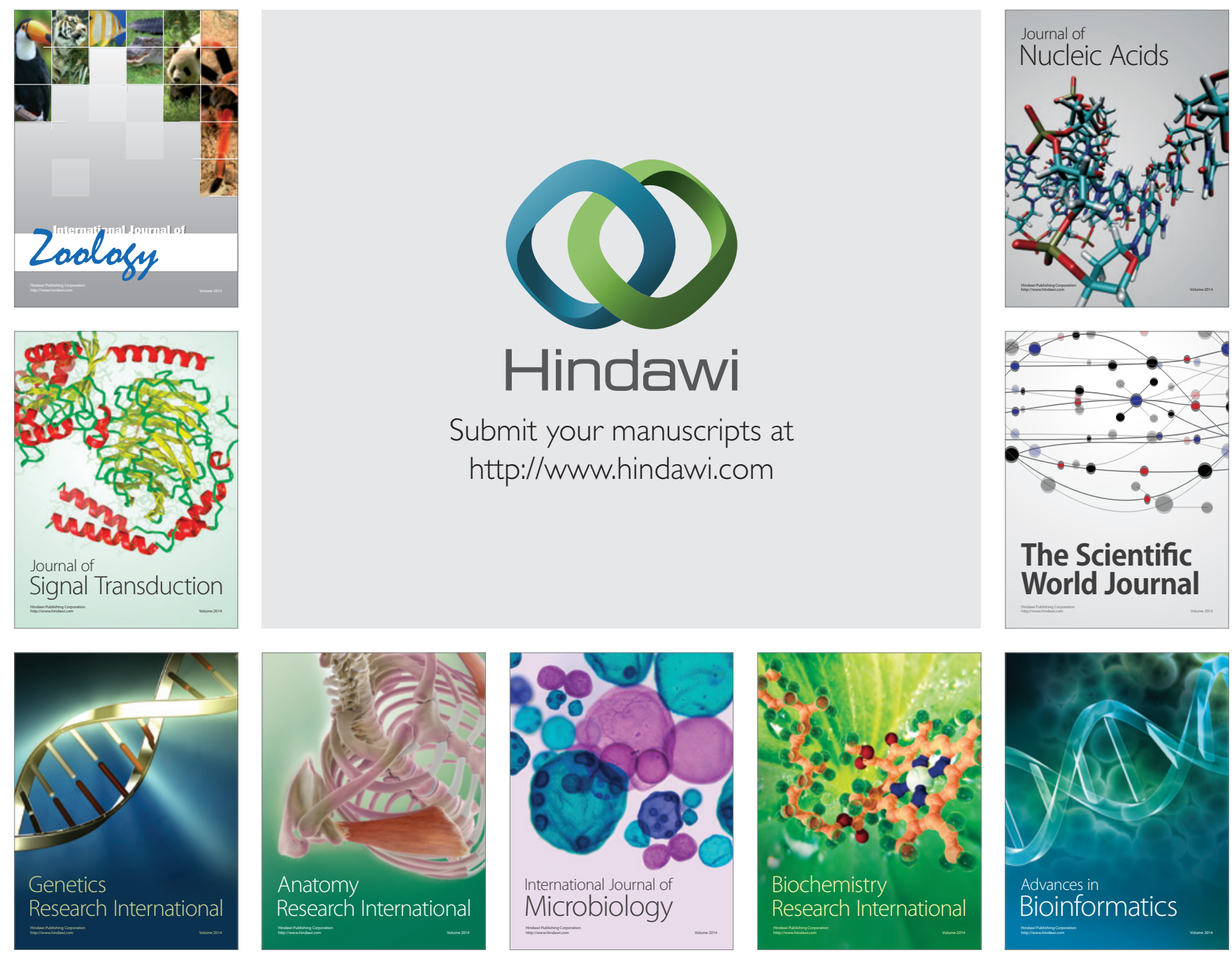

The Scientific World Journal
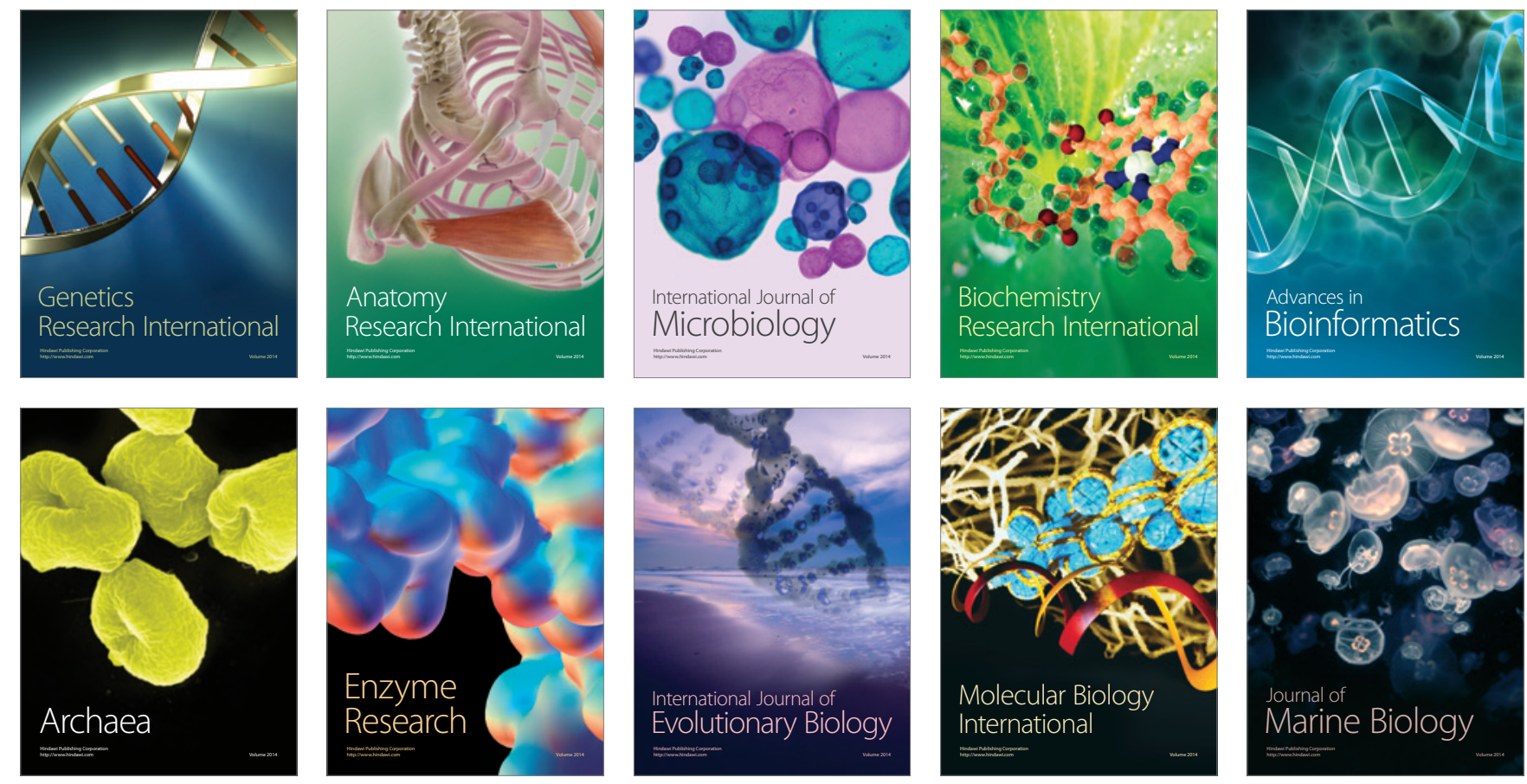